\title{
Normalized glucose variability by Low Carbohydrate Diet (LCD) in CGM study
}

Muneta $\mathrm{T}^{1,2}$, Kawaguchi $\mathrm{E}^{1,2}$, Hayashi $\mathrm{M}^{1,2}$, Bando $\mathrm{H}^{2,3}$, Ebe $\mathrm{K}^{2,4}$

${ }^{1}$ Muneta Maternity Clinic, Chiba, Japan

${ }^{2}$ Japan Low Carbohydrate Diet Promotion Association (JLCDPA), Kyoto, Japan

${ }^{3}$ Tokushima University / Medical Research, Tokushima, Japan

${ }^{4}$ Takao Hospital, Kyoto, Japan

Corresponding Author: Hiroshi Bando, MD, PhD, FACP

Address: Tokushima University /Medical Research, Nakashowa 1-61, Tokushima 770-0943, Japan. Received date: 06 January 2019; Accepted date: 29 January 2019; Published date: 04 February 2019

Citation: Muneta T, Kawaguchi E, Hayashi M, et al., "Normalized glucose variability by Low Carbohydrate Diet (LCD) in CGM study", Asp Biomed Clin Case Rep, vol.2, no.s1: 22-27, 2019.

Copyright (C) 2019 Muneta T, Kawaguchi E, Hayashi M, et al., This is an open access article distributed under the Creative Commons Attribution License, which permits unrestricted use, distribution, and reproduction in any medium, provided the original work is properly cited.

\section{Abstract}

In diabetic practice, continuous glucose monitoring (CGM) has been more used for glucose variability. Authors have reported and developed the clinical study of Low Carbohydrate Diet (LCD) and Calorie Restriction (CR) through Japan LCD Promotion Association (JLCDPA). A diabetic case is presented with normalizing glucose variability by LCD meal checked by CGM. Case is 51 years female with type 2 diabetes mellitus (T2DM). At first visit, $\mathrm{HbA} 1 \mathrm{c}$ was $10.0 \%$, glucose was $288 \mathrm{mg} / \mathrm{dL}$, BMI 39.1, GOT $16 \mathrm{IU} / \mathrm{mL}$, HDL-C $33 \mathrm{mg} / \mathrm{dL}$, Triglyceride $152 \mathrm{mg} / \mathrm{dL}$. CR meal was provided on day- 1 to day- 5 and LCD meal with $12 \%$ carbohydrate on day- 6 to day-13. Average glucose value from CGM was $292 \mathrm{mg} / \mathrm{dL}, 235 \mathrm{mg} / \mathrm{dL}, 160 \mathrm{mg} / \mathrm{dL}, 140 \mathrm{mg} / \mathrm{dL}, 124 \mathrm{mg} / \mathrm{dL}$ in day $3,5,7,9,11$ respectively.

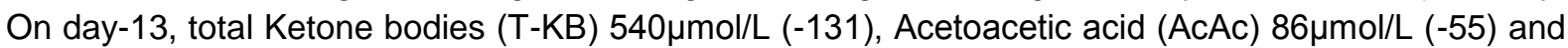
3 -hydroxybutyric acid (3-OHBA) $454 \mu \mathrm{mol} / \mathrm{L}(-85)$. Weight reduction was $5 \mathrm{~kg}$ on day-14 and $11.2 \mathrm{~kg}$ on day-70 with BMI 34.6. Thus, LCD showed a remarkable glucose-lowering effect in short term. FreeStyle Libre (Abbott, USA) seems to be a useful apparatus for monitoring the detailed fluctuation of blood glucose. These results would become fundamental and reference data and contribute to the $L C D$ research development in the future.

\section{Keywords:}

3-Hydroxybutyric Acid (3-OHBA); Ketone Bodies; Continuous Glucose Monitoring (CGM); Japan LCD Promotion Association (JLCDPA); FreeStyle Libre

\section{Abbreviation:}

LCD: Low Carbohydrate Diet; T2DM: Type 2 Diabetes Mellitus; CR: Calorie Restriction; JLCDPA: Japan LCD Promotion Association; AcAc: Acetoacetic acid; 3-OHBA: 3-Hydroxybutyric Acid

\section{Introduction}

Medical problems concerning diabetes, obesity and metabolic syndrome have been crucial and necessary to manage in many countries worldwide [1]. Adequate nutritional treatment is the fundamental therapy for those health problems [2]. Calorie restriction (CR) meal is formerly one of the standard therapy. After that, low carbohydrate diet (LCD) has been introduced to the medical and health field and was initiated by Atkins and Bernstein [3,4]. Successively, LCD has been prevalent and 
Citation: Muneta T, Kawaguchi E, Hayashi M, et al., "Normalized glucose variability by Low Carbohydrate Diet (LCD) in CGM study”, Asp Biomed Clin Case Rep, vol.2, no.s1: 22-27, 2019.

developed widely until now.

After that, the medical evidence of LCD was reported by investigators [5]. They include Dietary Intervention Randomized Controlled Trial (DIRECT) Group presenting LCD efficacy until 2 and 4 years $[5,6]$. The definition of LCD includes a rather wider area, and various levels of LCD has been tried and reported for years [7]. Furthermore, large scale studies concerning the clinical effect of LCD was presented, such as NIPPON DATA80 (National Integrated Project for Prospective Observation of Noncommunicable Disease and Its Trends in the Aged 1980) Research Group and the Prospective Urban Rural Epidemiology (PURE) study [8,9].

Associated with the research development of LCD, there have been some changes to the guidelines in several international diabetic societies. One of the controversies would be the recommended $\mathrm{HbA} 1 \mathrm{c}$ value, concerning what degree of strict control of glucose variability would be necessary [10,11]. Research development of LCD will contribute to the discussion in the future because LCD improves the average of blood glucose and Mean Amplitude of Glycemic Excursions (MAGE).

On the other hand, LCD in Japan was firstly introduced by Ebe, one of the authors [12]. After that, LCD has been gradually developed for diabetic patients. Furthermore, the author reported the important relationship among LCD, pregnant women, diabetes and ketone bodies [13]. In other words, a remarkably high level of blood ketone bodies were observed in pregnant women, neonates, placenta, and fetuses, and the various physiological roles of ketone bodies were reported [14].

The author has continued treating many cases with gestational diabetic cases with LCD $[13,14]$. Through our clinical treatment and research, there was a new case with type 2 diabetes mellitus (T2DM). Daily profile of blood glucose in the case was studied by continuous glucose monitoring (CGM), and it was remarkably improved by LCD meal for several days. The details of the case would be analyzed and reported in this article.

\section{Case Summary}

Present History:

The subject was 51 years old female. As past history, she has hypertension and allergic state for pollen allergy. She developed fatigue, sweating, frequent urination, feeling irritability and dizziness for some weeks. Then she thought the possibility of the climacteric syndrome in herself and she came to our clinic.

Urgent examination for diabetes showed that blood glucose was $288 \mathrm{mg} / \mathrm{dL}$ and $\mathrm{HbA} 1 \mathrm{c}$ was $10.0 \%$. She was diagnosed as type 2 diabetes mellitus (T2DM).

\section{Examination:}

Physical examination showed in the following. Consciousness and vitals were normal. Lung, heart, abdomen and neurological were unremarkable. Her physique was stature $160 \mathrm{~cm}$, weight $100 \mathrm{~kg}$ and body mass index (BMI) was $39.1 \mathrm{~kg} / \mathrm{m}^{2}$.

Chest X-ray and Electrocardiogram (ECG) were normal. Urinalysis showed positive for glucose, negative for protein.

Blood biochemistry tests were as follows: GOT $16 \mathrm{U} / \mathrm{L}$, GPT 20U/L, total protein $7.1 \mathrm{~g} / \mathrm{dL}$, BUN $15 \mathrm{mg} / \mathrm{dL}$, Cre $0.6 \mathrm{mg} / \mathrm{dL}$, T-Cho $195 \mathrm{mg} / \mathrm{dL}$, HDL-C $33 \mathrm{mg} / \mathrm{dL}$, Triglyceride $152 \mathrm{mg} / \mathrm{dL}$, Fe $74 \mu \mathrm{g} / \mathrm{dL}$, UIBC $237 \mu \mathrm{g} / \mathrm{dL}$ (110-425), complete blood count; RBC $498 \times 10^{4} / \mu \mathrm{l}, \mathrm{Hb} 15.9 \mathrm{~g} / \mathrm{dL}$, WBC $7,600 / \mu l$. Others were unremarkable.

\section{Research Protocol}

In this study, the daily profile of blood glucose was investigated. For measurement of detail fluctuation of blood glucose, FreeStyle Libre [15] was applied for 2 weeks [16]. This medical apparatus is used for Continuous Glucose Monitoring (CGM) [17]. After many years of research, it has been made and delivered by Abbott Diabetes Care in several countries [15]. 
Citation: Muneta T, Kawaguchi E, Hayashi M, et al., "Normalized glucose variability by Low Carbohydrate Diet (LCD) in CGM study", Asp Biomed Clin Case Rep, vol.2, no.s1: 22-27, 2019.

For long years, authors have continued clinical research about LCD and CR. There has been a certain clinical study protocol for the meal of LCD and CR. CR includes the balance of three macronutrients with PFC ratio is $15: 25: 60$. This is the standard ratio of the recommended meal from Japan diabetes Association (JDA) [18].

In contrast, LCD meal was selected $12 \%$ of carbohydrate in calorie ratio, which has been called as super-LCD. Its definition was made and prevalent by Dr. Ebe et al. in Japan LCD Promotion Association (JLCDPA).

In this study, the subject was provided with the standard formula meal according to our research protocol. The schedule is as follows:

I. The subject was given $\mathrm{CR}$ meal from day-1 to day-5, including $60 \%$ of carbohydrate which is standard meal in Japan as per Japan Diabetes Association [18].

II. The clock time of three meals was at 0800 , $1200,1800 \mathrm{~h}$, respectively in regular schedule.

III. The subject was given super-LCD meal from day- 6 to day- 13 , including $12 \%$ of carbohydrate.

IV. Detail glucose variability in 24 hours a day was continued from day-1 to day-13.

\section{Course and Results}

Using the FreeStyle Libre, the result of CGM for a daily profile of blood glucose was shown in Fig1. Formula meal of $C R$ was given from day- 1 to day-5. The average blood glucose per day was $292 \mathrm{mg} / \mathrm{dL}$ on day- 3 , and $235 \mathrm{mg} / \mathrm{dL}$ on day- 5 , in which the average data was decreasing.

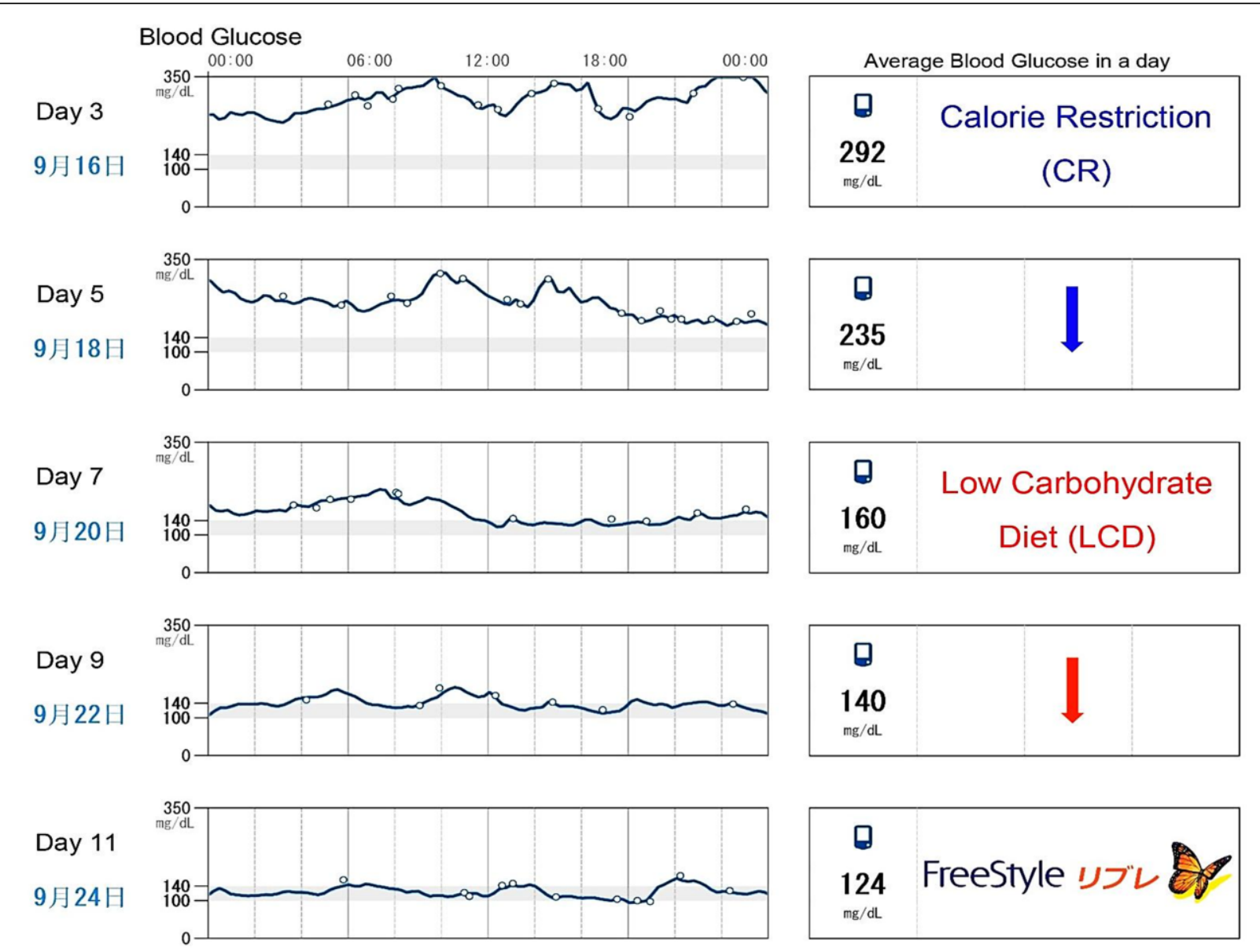

Fig-1: Daily profile of blood glucose from day 3 to 11 using CGM

Calorie restriction (CR) in day 1 to day 5 and Low carbohydrate diet (LCD) in day 6 to day 13 
On the other hand, formula meal of LCD was given from day- 6 to day-13. The average blood glucose per day was $160 \mathrm{mg} / \mathrm{dL}$ on day- 7 , $140 \mathrm{mg} / \mathrm{dL}$ on day- $9,124 \mathrm{mg} / \mathrm{dL}$ on day- 11 , respectively. This data showed a remarkable decrease in five days. On day-11, the daily profile of blood glucose showed almost normal range. Furthermore, the fluctuation between preprandial and postprandial blood glucose has been decreasing gradually and remarkably.

Blood values for ketone bodies on day-13 were measured, in which total ketone bodies $540 \mu \mathrm{mol} / \mathrm{L}$ (-131), Acetoacetic acid (AcAc) $86 \mu \mathrm{mol} / \mathrm{L}(-55)$, 3-hydroxybutyric acid (3-OHBA) $454 \mu \mathrm{mol} / \mathrm{L}(-85)$. All fragments of ketone bodies were elevated.

Until day-14, there were remarkable changes in the sign and symptom. Body weight was decreased to $5 \mathrm{kgs}$ and pretibial edema (PTE) was remarkably reduced until day-21. She felt the decrease of fatigue, hunger sensation, and stressful mood because of no limitation for eating meat and egg. Furthermore, she felt stable psychologically with the decreased opportunity to scold her children, indicating that her irritability was remarkably relieved. Her body weight was decreased to $88.8 \mathrm{~kg}$ with BMI $34.6 \mathrm{~kg} / \mathrm{m}^{2}$ in day70 , indicating clinical efficacy of LCD.

\section{Discussion and Conclusion}

With regard to LCD, Dr. Ebe started to apply LCD to diabetic patients in Japan, and developed LCD in Japan. He has established Japan LCD Promotion Association (JLCDPA) and we have continued to give general people correct and useful information of LCD through lots of occasions such as seminars, books, and reports in medical societies for years [19]. Simultaneously, LCD often brings elevated hyperketonemia. The physiological role of ketone bodies is extremely important in clinical practice. In the axis of a fetus-placenta-newborn-pregnant mother, KB can produce necessary energy instead of glucose [19].

In this study, blood levels of ketone bodies were measured for 7 days after starting to give
LCD meal to the subject. As a result, blood values of T-KB, AcAc, and 3-OHBA were elevated. The level of 3-OHBA which has the main function of the ketone body was 5 times higher than the standard value in this study.

The effects of ketone bodies (KB) has been gradually known with lots of beneficial function in metabolic and other axes in man [20,21]. They are

I. Elevated KB in blood is not the risky situation

II. Brain and muscle can use KB similar to glucose

III. KB generate much energy

IV. KB has anti-cancer effects [22].

Glucose intake $20-40 \mathrm{~g}$ per day will cause elevation of 3-OHBA of approximately $1 \mathrm{mM}$ $(1000 \mu \mathrm{mol} / \mathrm{L})$ with wide variations [23, 24].

In the diabetic patients provided with LCD meal, blood values of total ketone bodies showed 160 to $4,000 \mu \mathrm{mol} / \mathrm{L} \quad(0.16$ to 4 $\mathrm{mmol} / \mathrm{L}$ ) [25]. From this data, current total KB and $3-\mathrm{OHBA}$ would be in the range as expected.

In the history of diabetes care, recently introduced CGM has given a big impact [26]. Among them, FreeStyle Libre (Abbott, USA) has been a useful apparatus for CGM with a sensor-based method for glucose monitoring [27]. With CGM, the frequency of hypoglycemia in type 1 diabetes was reduced [28]. Furthermore, blood glucose fluctuation could be revealed in type 2 diabetes [29].

Practical data on CGM has been accumulated for long years. Clinical and Laboratory Standards Institute (CLSI) announced the CGM guidelines [30]. Furthermore, international standardization has continued the researches on the precision absolute relative difference (PARD) and mean absolute relative deviation (MARD) [31, 32].

From the current data on day-3, the blood glucose has risen from $230 \mathrm{mg} / \mathrm{dL}$ to 
Citation: Muneta T, Kawaguchi E, Hayashi M, et al., "Normalized glucose variability by Low Carbohydrate Diet (LCD) in CGM study”, Asp Biomed Clin Case Rep, vol.2, no.s1: 22-27, 2019.

$350 \mathrm{mg} / \mathrm{dL}$, and the difference between preprandial and postprandial glucose is $120 \mathrm{mg} / \mathrm{dL}$. In the case of T2DM, blood glucose is said to increase by $3 \mathrm{mg} / \mathrm{dL}$ per $1 \mathrm{~g}$ carbohydrate intake. Therefore, it is presumed that about $40 \mathrm{~g}$ of carbohydrate was ingested. On the other hand, on day-11, there is almost no difference between preprandial and postprandial glucose value. This seems to be related to decreased carbohydrate intake by LCD, increased insulin secretion response and decreased insulin resistance.

In summary, blood glucose decline was found in the patient with T2DM in a short period by LCD. The difference between preprandial and postprandial glucose, mean glucose and MAGE were decreased. Further, weight reduction was shown $11.2 \mathrm{kgs}$ in 10 weeks. These results suggest the increase of insulin secretion and a decrease of insulin resistance by the effect of LCD in a short period, with the useful data of a clinical application of LCD for future research.

\section{References}

[1] Ebe K, Bando H, "New era of diet therapy and research including Low Carbohydrate Diet (LCD)". Asp Biomed Clin Case Rep, vol.2, no.s1: 1-3, 2018.

[2] Bando $\mathrm{H}$, "Recent problems for the elderly life - diabetes, dementia, frailty". J Diabetes Metab Disord Control, vol.5, no.5: 167-69, 2018. [3] Atkins RC, "Dr. Atkins' diet revolution". Bantam Books, New York: ISBN-10: 0553271571, ISBN-13: 978-0553271577, 2018.

[4] Bernstein RK, "Dr. Bernstein's Diabetes Solution". Little, Brown and company, New York: ISBN-10: $0316093440, \quad$ ISBN-13: 9780316093446, 1997.

[5] Shai I, Schwarzfuchs D, Henkin Y, et al., "Weight Loss with a Low-Carbohydrate, Mediterranean, or Low-Fat Diet". N Engl J Med, vol.359, no.3: 229-41, 2008.

[6] Schwarzfuchs D, Golan R, Shai I, "Four-year follow-up after two-year dietary interventions". N Engl J Med, vol.367, no.14: 1373-74, 2012.

[7] Feinman RD, Pogozelski WK, Astrup A, et al., "Dietary carbohydrate restriction as the first approach in diabetes management: Critical review and evidence base". Nutrition, vol.31, no.1: 1-13, 2015

[8] Nakamura Y, Okuda N, Okamura T, et al., "Low-carbohydrate diets and cardiovascular and total mortality in Japanese: a 29-year follow-up of NIPPON DATA80". Br J Nutr, vol.112, no.6: 916-24, 2014.

[9] Dehghan M, Mente A, Zhang X, et al., "Associations of fats and carbohydrate intake with cardiovascular disease and mortality in 18 countries from five continents (PURE): a prospective cohort study". Lancet, vol.390, no.10107: 2050-62, 2017.

[10] American College of Physicians, "Clinical Guidelines and Recommendations": 2017.

[11] American Diabetes Association, "Pharmacologic Approaches to Glycemic Treatment: Standards of Medical Care in Diabetes-2018". Diabetes Care, vol.41, Suppl.1: S73-S85, 2018.

[12] Ebe K, Ebe $Y$, Yokota S, et al., "Low Carbohydrate diet (LCD) treated for three cases as diabetic diet therapy". Kyoto Medical Association Journal, vol.51: 125-29, 2004.

[13] Muneta T, Kawaguchi E, Matsumoto M, et al., "The effect of low carbohydrate diet (LCD) for gestational diabetes and its verification: Is hyperketonemia clinically due to LCD risky? (2nd report)". J Metab Clin Nutri, vol.17: S-203, 2014.

[14] Muneta T, Kawaguchi E, Nagai $Y$, et al., "Ketone body elevation in placenta, umbilical cord, newborn and mother in normal delivery". Glycative Stress Research, vol.3, no.3: 133-40, 2016.

[15] Abbott Diabetes Care:

https://www.myfreestyle.com/freestyle-libre-procgm-system

[16] Bolinder J, Antuna R, Geelhoed-Duijvestijn $P$, et al., "Novel glucose-sensing technology and hypoglycaemia in type 1 diabetes: a multicentre, non-masked, randomised controlled trial". The Lancet, vol.388, no.10057: 2254-63, 2016.

[17] Haak T, Hanaire H, Ajjan R, et al., "Flash Glucose-Sensing Technology as a Replacement for Blood Glucose Monitoring for the Management of Insulin-Treated Type 2 Diabetes: a Multicenter, Open-Label Randomized Controlled Trial". Diabetes Therapy, vol.8, no.1: 55-73, 2016.

[18] Japan Diabetes Association, "Diabetes 
Citation: Muneta T, Kawaguchi E, Hayashi M, et al., "Normalized glucose variability by Low Carbohydrate Diet (LCD) in CGM study", Asp Biomed Clin Case Rep, vol.2, no.s1: 22-27, 2019.

clinical practice guidelines based on scientific evidence": 2013.

[19] Muneta T, Fujisawa S, Arai K, et al. "LCD is effective by super doctors". Pia Mook Book, Tokyo, Japan: 2018.

[20] Watanabe S, "Wellness fasting and hyperketosis". Diabetes Res Open J, vol.2, no.2: e10-13, 2016.

[21] Paoli A, Rubini A, Volek JS, et al., "Beyond weight loss: A review of the therapeutic uses of very-low-carbohydrate (ketogenic) diets". Eur $J$ Clin Nutr, vol.67, no.8: 789-96, 2013.

[22] Hashim SA, Vanltallie TB, "Ketone body therapy: from the ketogenic diet to the oral administration of ketone ester". J Lipid Res, vol.55, no.9: 1818-26, 2014.

[23] Cahill GF Jr, "Fuel metabolism in starvation". Ann Rev Nutr, vol.26: 1-22, 2006.

[24] Watanabe S, Hirakawa A, Aoe S, et al., "Basic ketone engine and booster glucose engine for energy production". Diabetes Res Open J, vol.2, no.1: 14-23, 2016.

[25] Bando H, Koji E, Muneta T, et al., "Investigation of Elevated Ketone Bodies in Low Carbohydrate Diet (LCD)". Intern Med, vol.7, no.6: 260, 2017.

[26] FreeStyle Libre Software: https://www.freestylelibre.us/.

[27] Edge J, Acerini C, Campbell F, et al., "An alternative sensor-based method for glucose monitoring in children and young people with diabetes". Archives of Disease in Childhood, vol.102, no.6: 543-49, 2017.

[28] Beck RW, Riddlesworth T, Ruedy K, et al., "Effect of continuous glucose monitoring on glycemic control in adults with type 1 diabetes using insulin Injections: The DIAMOND Randomized Clinical Trial”. JAMA, vol.317, no.4: 371-78, 2017.

[29] Rodbard D, "Continuous glucose monitoring: a review of successes, challenges, and opportunities". Diabetes Technol Ther, vol.18, Suppl.2: S23-213, 2016.

[30] Klonoff D, Bernhardt P, Ginsberg GH, et al, "A performance metrics for continuous interstitial glucose monitoring; approved guideline". Ed by Institute CalS, USA, CLSI: 1-57, 2008.

[31] Liebl A, Henrichs HR, Heinemann L, et al., "Continuous glucose monitoring working group of the working group diabetes technology of the German diabetes association: Continuous glucose monitoring : evidence and consensus statement for clinical use". J Diabetes Sci Technol, vol.7: 500-19, 2013.

[32] Obermaier K, Schmelzeien-Redeker G, Schoemaker M, et al., "Performance evaluations of continuous glucose monitoring systems: precision absolute relative deviation is part of the assessment". J Diabetes Sci Technol, vol.7: 82432, 2013.

Keywords:3-Hydroxybutyric Acid (3-OHBA); Ketone Bodies; Continuous Glucose Monitoring (CGM); Japan LCD Promotion Association (JLCDPA); FreeStyle Libre 